\title{
Country Love (day 1)
}

\author{
Pamela Lofts
}

\begin{abstract}
After Christmas I went out along Undoolya road as I often do towalk the dog I turned into one of the bush tracks and was drawn to a bright green car in the red sand with the doors open like flags Lots of bunched up clothing was scattered around and my heart missed a beat because it looked like a body lying on the ground
\end{abstract}

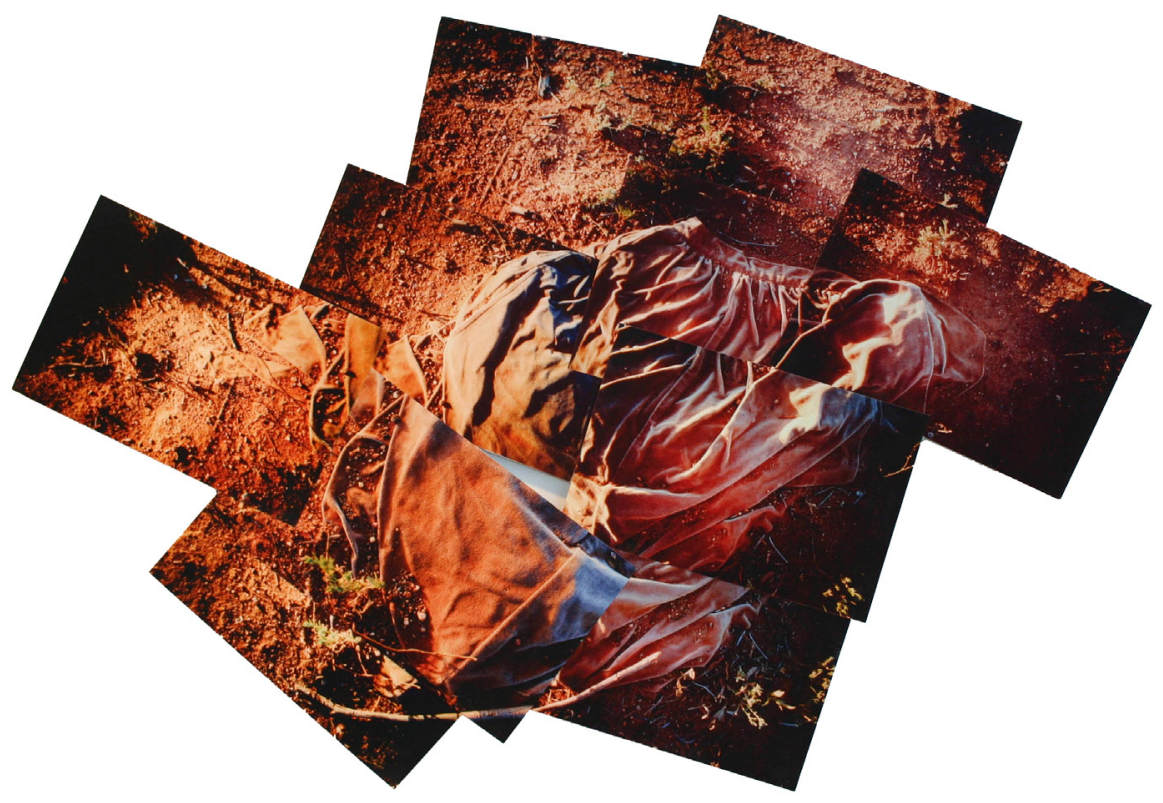


The scene had the feeling of something violent having just happened I went up to the clothing and was relieved to discover that it was just a heap of clothes

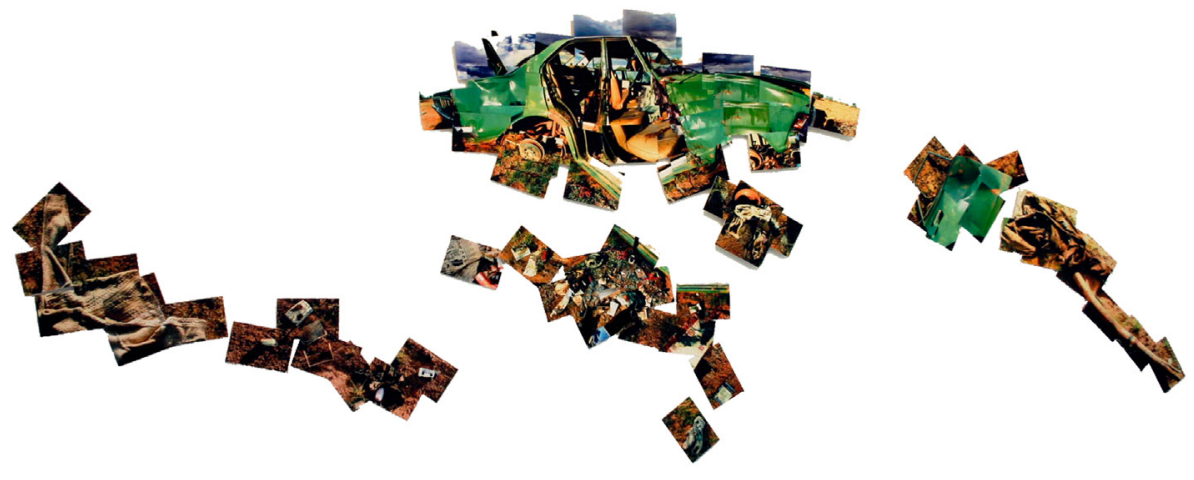

A red jumper a green jumper some crushed velvet thing.. maybe a cloak.. a fawn cableknit jumper

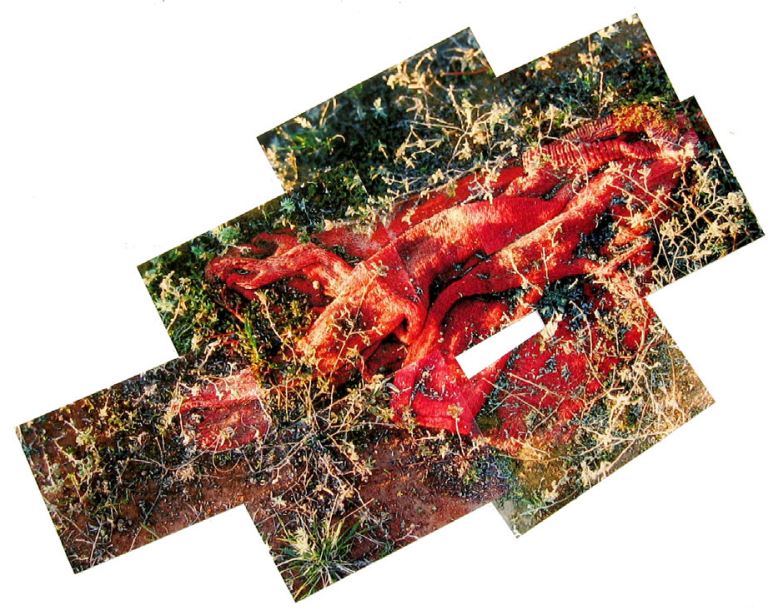


A bit further from the car was a broken Chinese bowl a couple of Moselle casks two orange enamel plates and a cluster of tampons swollen from the recent rain and looking like marshmallows

A tape Country Love had unravelled and slithered like a slippery snake over a woollen beanie and a pair of screwed up black underpants

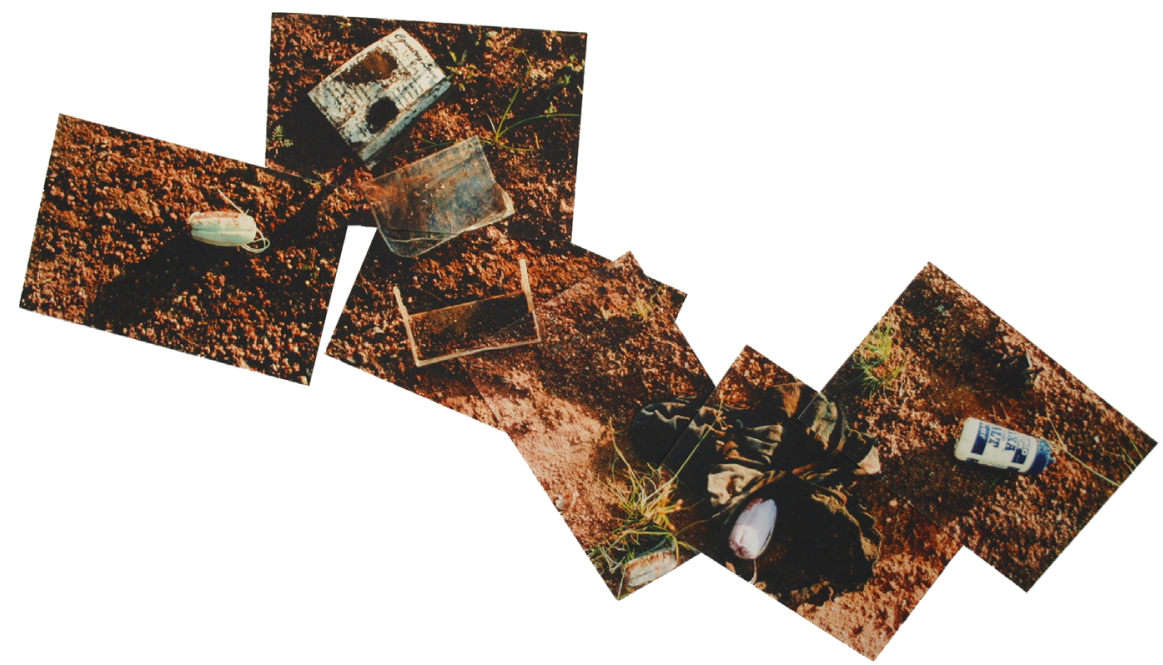

Inside the car which smelt of essential oils musky and thickwerebeads mosquito coil boxes and abook on Bud-

dhism A broken didgeridoolay on the front seat amongst shattered glass 


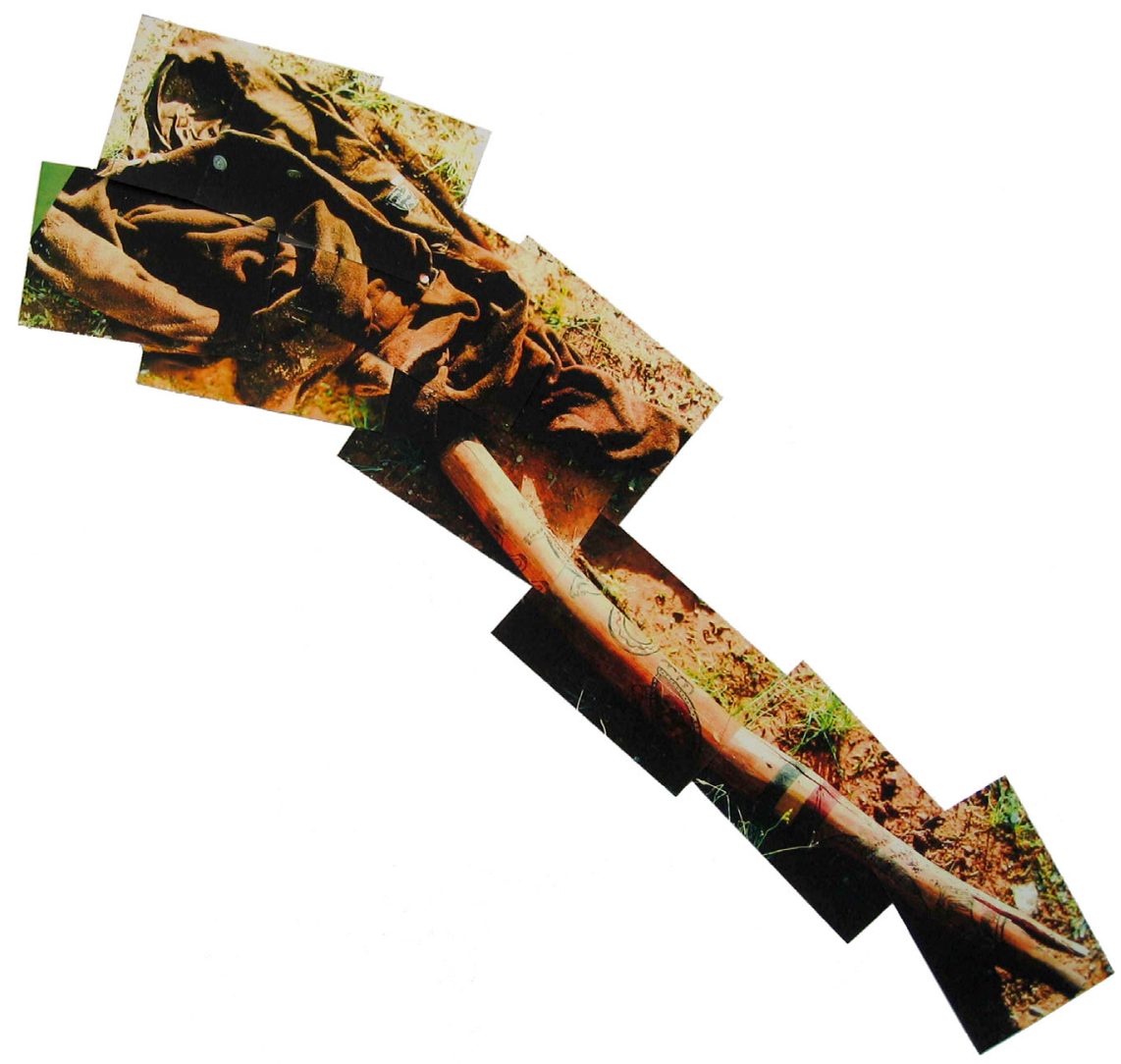

The boot was open showing a recent newspaper The astrology page predicted 'Aries are headed off to distant or remote and exciting places therewon't be much you cando with the rest of the day because everything will be so awkwardly placed. 


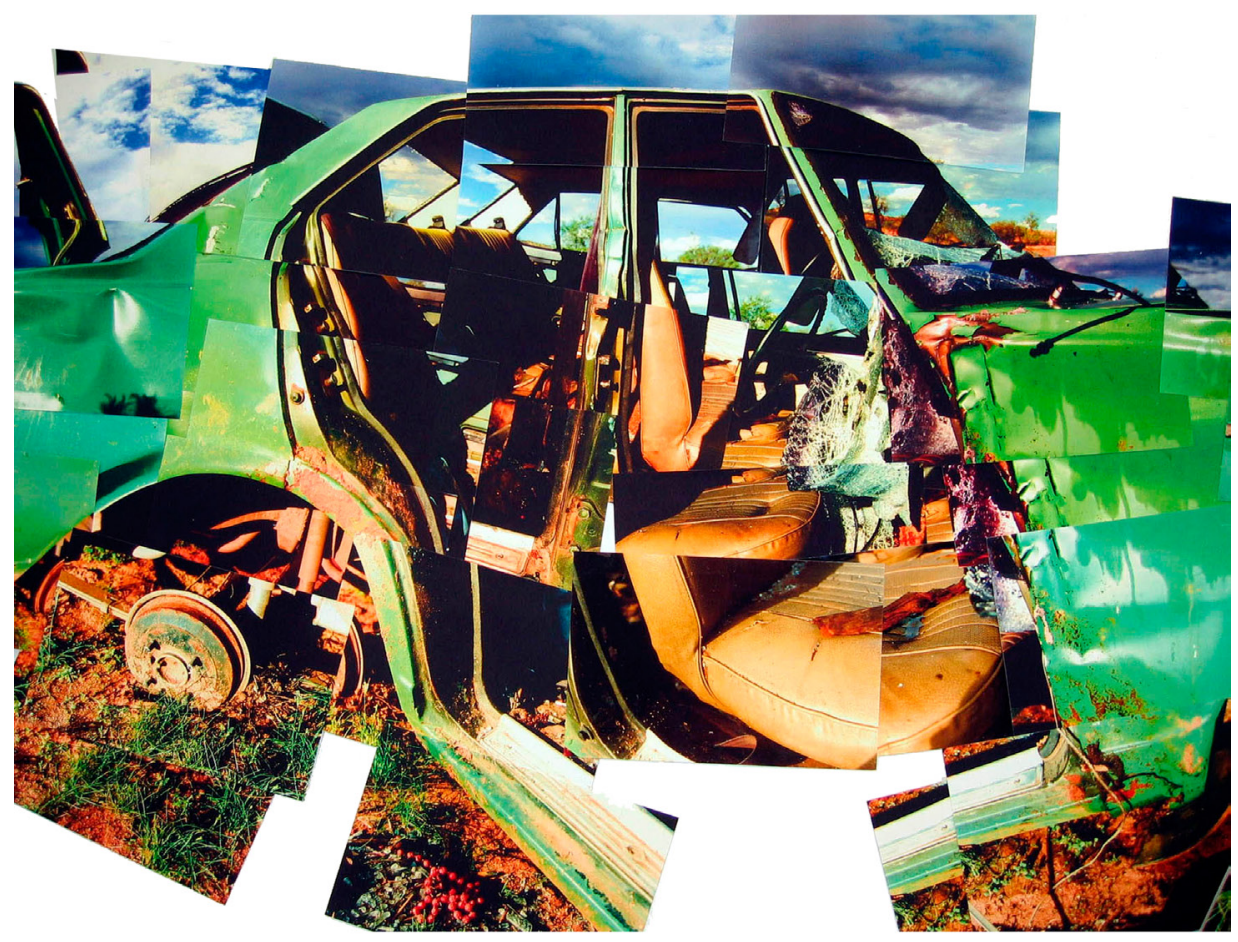

A Iong way from home I thought. 